The final publication is available at link.springer.com via http://dx.doi.org/10.1007/s10734-017-0190-5 


\title{
Why lecturers still matter: the impact of lecturer-student exchange on student engagement and intention to leave university prematurely
}

Authors:

Ben Farr-Wharton*, - Management Discipline Group, University of Technology, Sydney

Michael B. Charles -School of Business and Tourism, Southern Cross University, Bilinga

Robyn Keast, Professor - School of Business and Tourism, Southern Cross University, Bilinga

Geoff Woolcott - School of Education, Southern Cross University, Lismore

Daniel Chamberlain - School of Psychology and Public Health, La Trobe University, Melbourne

\begin{abstract}
This research examines the impact of lecturer-student exchange (student-LMX) on engagement, course satisfaction, achievement and intention to leave university prematurely for 363 students in one Australian university. Survey and Grade Point Average (GPA) data were collected from domestic undergraduate first- and second-year students and analysed using structural equation modelling. The results indicated that student's levels of engagement and course satisfaction fully mediated the relationship between student-LMX and intention to leave university, when demographic and socio-economic factors were controlled for. In an era when low student engagement and attrition is often attributed to individual demographic factors, and lecturers are under increasing threat of being replaced by technology, this research offers compelling evidence regarding the role of lecturer-student relationships in enhancing tertiary student outcomes.

*denotes corresponding author: Benjamin.farr-wharton@uts.edu.au
\end{abstract}

\section{Keywords:}

Retention, Student-centred Learning, Lecturers, Achievement, Engagement, student-LMX

Higher Education

DOI 10.1007/s10734-017-0190-5 


\section{Introduction}

There is little agreement regarding the antecedents of student engagement and retention in higher education. It could be argued that one of the key reasons for this deficit is that previous research (both qualitative and quantitative) has tended to privilege or amplify the effect of one or a particular set of cause variables over others. This has led to a debate that is easily distorted through selective or incomplete evidence. Over time, a particularly dominant stream of student engagement and retention research in higher education has emerged that focuses on the correlation between select student demographic variables (including economic status, educational preparedness, gender, or membership within a marginalised group) with academic performance and retention outcomes. Students classified as belonging to one or more of these categories are labelled as being at risk. In several studies, such as those of Christie et al. (2015) and Scott $(2005,2009)$, single at risk factors including, for example, economic background and education preparedness were significantly correlated with student attrition. Yet, when compared with other research, models that only use at risk variables appear to exclude other important variables central to student engagement and retention, such as the support provided by lecturing staff, course satisfaction and student achievement (Willcoxson et al. 2011).

This study examines an often-overlooked, yet potentially crucial, factor in the student engagement and retention debate: the issue of lecturer-student relationships. In our study, we examine the impact of such relationships on a range of student outcomes, including engagement, course satisfaction, achievement and intention to leave university prematurely. To advance a more comprehensive correlation model of student engagement and retention, our analysis also controls for a range of student at risk factors so that the significance of the former constructs can be captured. To date, research conceptualising the lecturer-student relationship through a leader-member exchange (LMX) theoretical lens is in its infancy. In the context of university education, student-LMX (as it is referred to) concerns the relationship formed between students and their teaching staff (lecturers and tutors) through learning interactions and activities (which occur in lectures, tutorials and facilitated online forums). Previous research by Jacques et al. (2012) has linked student-LMX to academic achievement, while a similar study by Mosley et al. (2014) found the variable to be important in student learning in a broader sense. The study reported herein builds on this previous research to position student-LMX as an important element of a learner-centred pedagogy, with the ability to influence engagement and retention outcomes.

\section{Student Retention: problems, programs and understandings}

Student attrition in higher education is a global issue and, as a result, understanding the reasons why students leave university prematurely has become a frequent theme in teaching and learning research and practice. In Australia, overall university student retention sits at 73.6\% (Edwards and McMillan 2015). Taken as a general indicator of overall tertiary education sector performance and efficiency, such a result might be regarded as quite poor; however, similar completion rates can be found in broadly comparable countries such as the United Kingdom (79\%), Germany (75\%), the Netherlands (72\%), and New Zealand (68\%) (OECD 2013). In a higher education funding environment where more must be done with less (Vaira 2004), and where addressing student engagement and retention has the potential to enhance the financial sustainability of traditional higher education providers in the face of lower-cost education provision models (Schneider 2010), determining the most-cost effective way of enhancing student retention is becoming increasingly paramount. Notwithstanding this 
economic imperative, enhancing student participation in higher education has undoubted benefits for the graduates themselves (in terms of employment prospects, and ethical and critical reasoning skills), and the broader society.

Pertinent research examining the issue of student attrition in higher education over the last decade and a half can be generally categorised into one of two perspectives centred either on: a) student inadequacies that lead to poor engagement and attrition; or b) institutional mechanisms geared towards enhancing engagement and retention. Focusing initially on the first perspective, Christie et al. (2004), in the Scottish context, associated students' intention to leave university with their economic status, lack of fit with the institution, poor choice of course pathway, and limited access social support. Wilcox et al. (2005) indicated that a student's ability to make compatible friends (socialisation) and their living arrangements (related to economic status) contribute to their willingness to stay at university. An Australian study by Taylor and Bedford (2004), who examined staff perceptions concerning why students exit tertiary studies prematurely, identified an array of student characteristics corresponding to disengagement and ultimately attrition. These characteristics include a lack of academic skills, poor study management skills, poor institutional fit, immaturity and poor school achievement. As the same researchers observed, 'Non-completion is seen as a major issue facing staff, yet they appear to perceive it as an issue that is beyond their control' (Taylor and Bedford 2004, p. 391). In the case of New Zealand, Scott $(2005 ; 2009)$ correlated attrition with various demographic factors, including gender, ethnicity, age, and students who have low grade point averages (GPA). Yet, with reference to the broader body of research, it is difficult to ascertain whether these factors are salient against other unmeasured characteristics, such as economic status and learning experience (Forsman et al. 2014). The same criticism can also be applied to the study of Edwards and McMillan (2015), who found that students belonging to one or more at risk groups were generally less likely to complete their tertiary qualification.

There have been several studies examining the impact of engagement and retention interventions on student outcomes. In particular, interventions have focussed on advancing student equity (i.e., programs targeting students from disadvantaged backgrounds) and enhancing students' study skills and preparedness. Such interventions have generally sought to bridge the gap for students belonging to an at risk category. Yet several studies have also included interventions that were open to all students. For example, a United States-based study by Sanchez et al. (2006) indicated that a first-year mentoring program had a very limited impact on student achievement and graduation behaviour, irrespective of student's level of educational preparedness. Similarly, Jamelske (2009), when researching longitudinal, first-year intervention data (open to all students) from one U.S. university, discovered that intervention programs had a slight impact in improving the grade point average (GPA) of students, but had no direct impact on their retention. Jamelske (2009) concluded that the benefit of intervention programs is more prevalent for students not belonging to an at risk group. In combination, this body of research appears to suggest that the impact of retention interventions on retention outcomes may be quite limited, with all students potentially benefitting from certain types of interventions.

A later study by Willcoxson et al. (2011) offers one possible as to reasons why the impact of retention interventions may be quite limited. These researchers tracked the support needs (influencing intention to leave at university) of a random selection of students in first, second and third years of undergraduate education across six universities in Australia. They found that the factors affecting students' intention to leave university were different and varied according to the year of study (i.e., first, second or third year), the type of course in which 
they were enrolled, the student's mode of study (distance, on campus or mixed), and the particular campus at which they were studying. Accordingly, and with so many variables at play that could have an effect on a student's intention to leave, it stands to reason that retention interventions alone may only have a limited impact. More broadly, Willcoxson et al. (2011) found that the engagement and retention of first-year students was related to their levels of educational and psychological readiness, together with academic integration. Yet, as students progressed through their studies, having learnt how to balance competing demands, the factors predicting retention shifted to a need for teacher support and academic confidence. However, for some of the six universities included in Willcoxson et al.'s (2011) study, these issues were not prevalent at all. This was likely because the institutional and/or cohort characteristics meant that these issues were not present, or not significant in their influence on engagement and retention.

An often-neglected narrative in the student engagement and retention debate concerns the impact of a learner-centred tertiary study experience. Zepke et al. (2006, p. 587) categorised universities as being learner-centred when the 'interests of diverse students are at the centre of teaching and institutional processes.' Yorke and Thomas (2003) examined the institutional arrangements aligned with a learner-centred pedagogy. Their sample included six universities in the United Kingdom that generated above average-retention scores, yet also had a higher percentage of students belonging to at risk groups. The researchers found that universities espousing a learner-centred model had implemented a number of systems that contributed to higher than average retention rates. Such systems included: early intervention programs for at risk students; curriculum that was consciously non-elitist; tutoring that was personal and focussed on responding to student needs; and, a pragmatic and accepting approach towards students' need to undertake part time work. Yorke and Thomas (2003) argued that a studentcentred agenda is largely set by the organisational culture of respective institutions, and that this informs the approach taken by university teachers (lecturers and tutors) towards their students. In effect, a university, having limited resources to direct towards retention activities, can only do so much to cater for the individual needs of all the diverse at risk groups, particularly when the availability of specialised support for such groups cannot be firmly linked to predicting student retention and success. Hence, the implementation of a studentcentred approach falls to university teaching staff who engage most frequently with the students.

\section{Student Leader-Member Exchange}

Leader-member exchange (LMX) theory seeks to explain the ways in which leaders (in this case, lecturers), through their own behaviour and attributes, are able to direct the behaviour of subordinates belonging to a member group (Cropanzano and Mitchell 2005). In the first instance, a leader 'provides the first signal of a desire for a closer relationship to subordinates' (Cropanzano and Mitchell 2005, p. 888). As subordinates reciprocate, a mutually beneficial exchange relationship develops over time. Through reciprocity, the ongoing process of give and take, the subordinates benefit as a result of having enhanced access to the resources and attention of the leader. Leaders benefit in turn as they can direct subordinates to complete tasks with greater influence. However, not all subordinates benefit from LMX. Leader and follower relationships can be contingent on the personal characteristics of the leader and their follower(s); that is, if they share characteristics such as being of a similar age group, or have similar social values (Graen and Uhl-Bien 1995). If subordinates do not develop a reciprocal relationship with their leader, they are said to belong to the out-group. Those in the out-group not only have diminished support, given that the leader will direct more attention and 
assistance to members of the in-group, but also have to deal with negative reinforcement generated by the leader, and the leader's in-group followers.

In view of the above, we argue that the LMX relationship is a central consideration in the deployment of a learner-centred pedagogy within universities. In contrast with more organisational-level learner-centred considerations (which may or may not directly influence students), LMX exists at the interface between the student and their learning. In this way, Jacques et al. (2012) contend that the LMX relationship is applicable to the university lecturer-student relationship as teaching staff direct student's learning behaviour through the relationships that they form. These relationships can be reciprocal; for example, where a member of the lecturing staff reviews a student's draft and offers feedback, only to note the incorporation of said reviews in the final submission. Yet they can also be transactional; for example, where lecturers set expectations for performance, and reward those who meet or exceed such expectations (and ignore or disregard those who do not meet these expectations). However, in comparison to the form of LMX appearing in organisations between managers and their staff, in a university context, student-LMX is much more temporal. This is because the degree of interaction that students have with their lecturers is not likely to exceed several hours a week, over a confined semester period (usually between 10-16 weeks for Australian undergraduate students). On occasion, a student might have a lecturer for concurrent subjects and semesters throughout their degree, though this would depend on the number of staff employed within the faculty, and is likely to be the exception given the mass education focus of university education in Australia. In such a climate, students may perceive a range of different relationship strengths with each of their lecturers over the course of their degree. In this study, we conceptualise student-LMX as representing the overall relationship formed with the sum total of their lecturers over the course of their degree. Thus, a positive studentLMX relationship denotes that interactions between a student and their lecturers have generally (in the main) been positive, supportive and reciprocal.

\section{Student Engagement and Course Satisfaction}

Student engagement is a broad concept with multiple definitions. Our focus is on the notion of engagement as it applies to students' approach to their study, consistent with the research of Schaufeli et al. (2002). We adopt this perspective as, under this definition, engagement can be considered independent of the concepts of student achievement and retention. As a result, delineating these concepts is important when modelling statistical relationships between variables. Under this conceptualisation, engagement is comprised of three sub-components, these being vigour, dedication and absorption:

'Vigour is characterized by high levels of energy... while working; dedication is characterized by a sense of significance, enthusiasm, inspiration, pride and challenge; absorption is characterised by being fully concentrated and happily engrossed in one's work'

(Schaufeli et al. 2002, p. 468).

LMX has shown to be a precursor for engagement in workplace contexts (Graen and UhlBien 1995; Wayne et al. 1997). In the university context, we argue that the student-LMX relationship is likely to influence engagement, as students who reciprocate learningappropriate behaviours benefit from additional access to support and direction that may fuel vigour, dedication and absorption. Hence, we hypothesise that student-LMX is positively associated with engagement (hypothesis 1). 
A distinction can be made between the constructs of student engagement and course satisfaction within the context of university studies (Sevier 1996). Course satisfaction accounts for a student's positive or negative associations with the educational dimension of their tertiary studies (Elliott and Shin 2002). Paechter et al. (2010) note that students can clearly perceive when the coherence and structure of a course does not meet their expectations. Students' perceptions concerning the level of lecturer support is suggested by Richardson et al. (2007) as a precursor to course satisfaction. Furthermore, we contend that students with higher levels of engagement may also enjoy higher levels of course satisfaction, as they are progressing through their studies with more vigour and intensity. Yet, this vigour may also make them critical of their courses. This is because students may perceive gaps in the content that they are learning. Krishen (2013) found that student engagement was positively associated with course satisfaction, particularly when students felt that course content and associated learning activities were complimentary and meaningful. As a result, we propose herein that student-LMX is a key antecedent for a positive relationship between engagement and course satisfaction, as lecturers are responsible for positioning the content and learning activities for students. When appropriate consideration concerning the content and learning activities are present (controlled by the lecturer), it is foreseeable that engagement and course satisfaction is also enhanced. Thus, we hypothesise that student-LMX and student engagement is associated positively with course satisfaction (hypothesis 2).

\section{Student Achievement}

Jacques et al. (2012) found a small correlation between student-LMX and overall course grade $\left(\mathrm{R}^{2}=17, p<0.05\right)$. Yet, an insignificant association was found between student-LMX and a single, final test score (representing student achievement) in the study of Mosley et al. (2014). We contend that the study of Jacques et al. (2012) may be more applicable to our study, as overall course grade is a likely a more cognate measure with students' GPA (used in this study) than a single, final test score. Hence, we hypothesise that student-LMX may have a small, positive association with GPA (hypothesis 3).

\section{Intention to Leave University Prematurely}

One way to offer a predictive model of attrition is to account for students' intention to leave their studies prematurely (Sanchez et al. 2006; Willcoxson et al. 2011). Research shows that students who are exposed to learner-centred interventions are more committed to complete their study (Sanchez et al. 2006; Yorke and Thomas 2003). From this, we posit that studentLMX is negatively associated with students' intention to leave their studies prematurely. Furthermore, the research of Schaufeli et al. (2002) has linked student engagement with intentions to persists in education. Also, students who are dissatisfied with their course may choose to discontinue, or look for other alternatives (Christie et al. 2004). Finally, Taylor and Bedford (2004) indicate that lecturers commonly cite poor student achievement as a reason why students leave their studies prematurely. Building from this research, we hypothesise that student-LMX, engagement, course satisfaction and student achievement are negatively associated with students' intention to leave their studies prematurely (hypothesis 4). While the supervisor-subordinate (LMX) relationship in university education is quite distinct from organisational contexts, positive associations are commonly found between these variables (LMX, engagement, satisfaction and intention to quit) in organisational research; for 
examples, see Jordan and Troth (2011) for the case of technical workers, and Brunetto et al. (2013) for the case of nurses.

As discussed above, a number of student demographic variables have also been shown to correlate with attrition. In our study, these variables are used as control variables (see below). This approach enables us to highlight the correlation strength of particular variables (such as student-LMX, engagement etc.) on students' intention to leave prematurely, when other at risk variables are accounted for.

\section{Indirect Mediation Effects}

A mediating variable acts to account more fully for the relationship between an independent and dependant variable by highlighting the change in variance when intervening (mediating) variables are modelled (Baron and Kenny 1986). We propose that work engagement, course satisfaction and GPA may mediate the relationship between student-LMX and intention to leave prematurely (hypothesis 5). To justify this claim, we suggest that, when engagement, course satisfaction and GPA are all high, these factors in combination act to enhance the negative association between student-LMX and intention to leave prematurely.

\section{Controlling for at risk factors}

As noted in the introduction, there are a multitude of studies that have correlated student attrition with gender and economic status factors, with female students, and students' who experience financial hardship being more likely to leave their studies prematurely (Edwards and McMillan 2015). In addition, a student's level of education preparedness, their mode of study (i.e., distance versus on-campus students), the year of their university study, and the extent to which they undertake work and activities outside of university, have all been shown to impact on retention indicators (Scott 2005; Scott 2009; Simpson 2013). Becker (2005, p. 274) points out that 'control variables are factors that researchers include in their work to rule out alternative explanations for their findings.' With respect to the aforementioned research, in operationalising our study we used a number of control variables to rule out the effect of alternate explanations regarding student's intention to leave prematurely. This includes the identified at risk factors of:

1. Economic status

2. Educational Preparedness

3. Gender

4. Study mode (Distance, online or blended)

5. The number work hours undertaken outside of university study

6. Study progression (first or second year)

Our hypotheses (and control hypotheses) are displayed in the following hypothetical model. Hypothesis 4 denotes direct paths, while hypothesis 5 represents indirect/mediation paths. 


\section{Method}

To examine the relationship between student-LMX, engagement, course satisfaction, achievement and intention to leave university prematurely, we collected psychometric selfreport survey data and GPA scores for first and second year domestic students in one Australian university. While a self-report survey method is often criticised as it can be prone to method variance, it remains one of the most practical mechanisms to collect data concerning an individual's attitudes, beliefs and behaviours across from a large sample of people (Richardson et al. 2009). To reduce the impact of method variance, care was taken in structuring the survey so as to group items under respective constructs; continuous, scaled and categorical variables were used; and we distributed different sets of questions over several pages, all of which are suggested measures by (Cascio 2012). We undertook a single item variance test to examine the potential impact of common method variance across our data. The test indicated that $29.7 \%$ of the variance was explained by one item, indicating a very low chance the method variance was present across the data (Richardson et al. 2009).

\section{Sample and instruments}

The survey was limited to domestic (Australian) students studying in their first and second year of their three- or four-year undergraduate bachelor degree (excluding those in their first semester as no GPA score was yet recorded). This group was selected as an intention to leave at this point of study could only be classified as premature - those in their third and fourth year would be close to their natural graduation point. International students were excluded at the request of the university. The online survey was opened to all 4,000 students fitting the criteria, for six weeks from the second week of the second semester of study in 2015. In total, 430 students returned the survey (in completed form). A possible explanation for this low response rate concerns the fact that the memo to students requesting participation in the research was sent through their student email account, which generally receives a high volume of general university communiqués that are habitually discarded.

To further refine our sample, we asked a categorical (yes/no) question in our survey - 'I am pursuing opportunities to study at another university.' Of the 430 students who answered the survey, 57 students answered 'yes' to this question. These samples were removed, meaning that, in our study, respondents expressing an intention to leave captured those students who intend to withdraw from their studies completely. Thus, the total sample size used in analysis was 363 samples. Hair et al. (2010) suggest that analysis using sample sizes of between 200 and 500 is optimal for structural equation analysis. This is because sample sizes above and below these thresholds are prone to type I and II errors, thus leading to an incomplete, or over-populated distribution curve.

Where available, our survey items drew from, and adapted, pre-validated psychometric instruments, and utilised a six-item Likert scale where 1 was 'strongly disagree', and 6 was 'strongly agree'. The questions related to each construct are provided in appendix one. Our measure for student-LMX adapted the frequently used seven-item LMX scale of Graen and Uhl-Bien (1995). The Cronbach's alpha for student-LMX in our study was .90, which is well above the prescribed threshold of .70 as suggested by Hair et al. (2010). We utilised a shortened 6-item engagement scale from Schaufeli et al. (2002), which had a Cronbach's alpha score of .88. We adapted the four-item intention to leave scale of Cammann et al. (1983) to the context of a student's intention to leave their university prematurely, which had a Cronbach's alpha score of .92 for our data. A scale was developed to account for students' 
levels of course satisfaction using Hinkin's (1998) framework for generating valid and robust psychometric instruments (see survey questions in the appendix). Through pre-testing items drawn from the literature, the course satisfaction construct contained four items and had a Cronbach's Alpha score of .89. A three-item scale to measure students' levels of educational preparedness was also developed. This had a Cronbach's Alpha score of .87. The economic status of students was measured using an six-item scale adapted from the perceived earnings scale of Farr-Wharton et al. (2015), which had a Cronbach's Alpha score of .93 for our data. Additional instrument reliability and validity information, highlighting the robustness of these instruments, is explored in the following section.

To collect data representing student's achievement, respondents indicated their student number, and this was matched with the latest GPA data kept on file at the university. The GPA data at the university in question is measured on a 7-point scale (7=High distinction, 6 =distinction, $5=$ credit, $4=$ =ass, $3=$ high fail, $2=$ fail, $1=$ low fail). In analysis, structural equation modelling (SEM) standardises all variables, hence this and other non-6-point scaled items were used in the structural model (see analysis below). Students' (non-study-related) work hours were grouped into six categories: $0,>10,>20,>30,>40,41<$ hours per week. Students' study mode contained five categories: completely on campus, mostly on campus, about half on campus, the majority online, and all units online. Gender had two categories, where codes of 1 and 2 represented male and female respectively.

\section{Instrument Reliability \& Validity}

The items for each instrument were subjected to confirmatory factor analysis in SEM. Through this process, the reliability of the scales was assessed using the composite reliability (CR) score, and the convergent and discriminant validity were assessed using the average variance extracted (AVE) scores and inter-construct reliability matrix, as is highlighted in Table I. All composite psychometric variables proved to be highly reliable, with composite reliability scores of above .07. Convergent validity was indicated with AVE scores for each construct being lower than .05 , and discriminant validity was present as the square root of the AVE was greater than inter-construct correlations, as displayed in Table I (these threshold figures were adopted from Hair et al. 2010). Q-Q plot scanning indicated no significant deviations from normality for all items, and the skewness and kurtosis were within acceptable normality thresholds of +2 and -2 (George and Mallery 2010).

[insert table I near here]

\section{Analysis Technique}

SEM analysis was utilised to examine the hypothesised relationships between tested constructs. SEM is regarded as one of the most advanced multivariate analysis tools, as hypothesised paths between different set of variables can be investigated, while goodness of fit thresholds provide a robustness indicator for the results (Hair et al. 2010). Goodness of fit is indicated when a model has a chi-squared over degrees of freedom (CMIN/DF) score of below 5, a correct fit index (CFI) of above .9, a Tucker-Lewis indictor (TLI) of above .9, and a root mean square error approximation (RMSEA) below .8 (Hair et al. 2010). The model fit indices of our analytical model were well within the acceptable thresholds, where the CMIN/DF was 2.180, the CFI was .923, the TLI was .911 and the RMSEA was .057. 


\section{Results}

\section{Sample description}

Of the 363 respondents, $72 \%$ were female $(n=262)$, and this closely matches the profile of undergraduates at the university, where of the $68 \%$ were female in 2015 . Furthermore, roughly $40 \%$ of the respondents $(n=145)$ undertook no paid work outside of their university studies; and 23\% undertook less than 10 hours per week (p/w), thus leaving the remaining $37 \%$ undertaking more than this. $40 \%$ of the sample undertook all of their studies on campus $(\mathrm{n}=146)$, and $38 \%$ undertook their studies only in online/distance mode $(\mathrm{n}=102)$; leaving the remaining $32 \%$ in a blended delivery format.

\section{Correlation analysis}

Construct means and correlations are displayed in Table II.

\section{[insert Table II near here]}

The correlation analysis indicates that intention to leave, course satisfaction, engagement and student-LMX are all significantly related. Of the control variables, gender and work hours per week have a small but significant relationship with intention to leave.

\section{Path Analysis \& Mediation Testing}

Hypotheses 1 and 2, which proposed a positive association between student-LMX, engagement and course satisfaction were supported. Indeed, student-LMX and engagement contributed to a significant portion of course satisfaction, as indicated by the $\mathrm{R}^{2}$ value of .67 . Only partial support for hypothesis 3 was found as there appeared to be no significant link between student-LMX and GPA, even though course satisfaction and engagement did have a small but significant relationship with this. However, course satisfaction had a negative association with GPA. Yet the $\mathrm{R}^{2}$ value of GPA is very small (.05), thereby indicating that the actual effect size was very small across the population.

Hypothesis 4 posited a negative association between student-LMX, engagement, course satisfaction and GPA with intention to leave. The results provide evidence in support of most of these paths; that said, no significant relationship was found between GPA and intention to leave. Furthermore, both student-LMX and engagement had an indirect relationship (through respective mediating variables) with intention to leave (see further discussion regarding mediation testing below).

\section{[insert Figure 2 about here]}

Mediation testing was undertaken to examine hypothesis 5. Mediation testing utilised the bootstrapped bias corrected standardised indirect effect test (undertaken at the 95\% confidence level, bootstrapped to 4000 samples), as prescribed by Shrout and Bolger (2002). The results, which highligh the direct and indirect estimates, together with the significance levels, are displayed in Table III. 
The results indicate a full double mediation effect, whereupon course satisfaction and engagement fully mediates the relationship between student-LMX and intention to leave university. In combination, these variables contributed to a small but notable portion of student's intention to leave prematurely, as indicated by an $\mathrm{R}^{2}$ value of .24 . This means that, for this sample, these constructs (in combination) predict $24 \%$ of a student's intention to leave university when the effect of the control variables are accounted for. While this outcome poses significant implications for universities and their lecturers (discussed below), it also highlights that the larger portion concerning why students desire to leave university are not accounted for in this model (76\%) - despite the inclusion of a broad variety of variables drawn from previous studies. In light of this, and for this sample at least, the contributing factors as to why students intend to leave university may be largely ascribed individually, and are therefore difficult to generalise to a broader population. However, further research, involving other samples and possibly additional variables, is needed to verify claim.

The control variables that were significant for student's intention to leave included work hours per week $(\beta=-.02, p<0.01)$ and gender $(\beta=-.12, p<0.001)$. The small negative correlation with work hours per week seems to indicate that those students not undertaking any paid work, and those working less hours, were slightly less likely to express a desire to leave. This validates the research of Simpson (2013). Yet, unlike the findings of Edwards and McMillan (2015), women were less likely to leave in this sample, although this may be due to the fact that the sample, and the university in question, had a higher portion of female students than male enrolled in undergraduate studies. Important to note is that the control variables, representative of at risk categories, had a much smaller impact on student's intention to leave university in comparison to the modelled student-LMX, engagement and course satisfaction constructs in combination. Notwithstanding the relatively small effect size of this model, the key contribution of this study is that it offers a potentially more robust understanding of the correlates of students' intention to leave university than studies that have only used a few at risk variables in isolation.

\section{Discussion}

The results indicate that the student-LMX relationship, and its flow on effect to engagement and course satisfaction, is significantly related to student's intention to leave university prematurely. If retention rates are a measure of organisational productivity, traditional Australian universities, together with many other universities globally, need to enhance retention to yield a more sustainable business model - the issue is that lecturers at such universities, in their efforts to assist with retaining students in their enrolled courses, might be doing so based on suppositions that are not wholly evidence based. This is particularly important given that each student not retained represents a significant cost for the education provider (and often the tax-payer by extension), especially given that considerable resources are invested in the education of such students. Equally, disengaged students who leave their studies prematurely may not receive the benefits associated with a higher education degree.

Notwithstanding the significant associations between student-LMX, student engagement and course satisfaction with intention to leave university prematurely, no association was observed in this study between student-LMX and GPA, and GPA and intention to leave university. Moreover, a positive association was found between engagement and GPA, yet a negative relationship was observed between course engagement and GPA. A possible explanation for this is that those students performing well in a course of study become dissatisfied as the overall challenge level for them is low. The results seem to suggest that 
high course satisfaction has a dual role for some students, because it has a significant negative association with intention to leave, but (for a smaller portion of the study sample) it is associated with a lower GPA. To some degree, this implies that students can enjoy high course satisfaction, even though their academic performance is not particularly robust. It could be argued that this shows evidence of mature reasoning skills on the part of the students concerned, as the value of learning (course satisfaction) can be high even when the outcome (GPA) is not.

\section{Implications for practice}

As noted earlier, institutional programs seeking to enhance student engagement and retention are common, yet they have not provided a panacea to the issue of poor student retention. Our findings may offer a reason for this, as the existing programs generally focus on alleviating perceived student inadequacies, or assisting socialisation within universities in order to improve student engagement. In contrast, enhancing the lecturer-student relationship is rarely put forward as a means for engagement interventions (Jacques et al. 2012). Moving beyond programs catering to at risk groups, our findings suggest that lecturer-student exchanges are of pivotal importance in engagement and retention modelling, and may therefore provide an additional avenue to instigate more robust retention programs. Moreover, our results suggest that, in combination, the association between student-LMX, engagement and course satisfaction with intention to leave prematurely was more pronounced than the modelled at risk factors. However, it is important that the results presented herein are not interpreted as a call to curtail current at risk retention programs, which clearly have an important role to play in the higher education landscape. Rather, developing LMX within the context of the lecture theatre or through other educational forums, such as on-line activities, may be regarded as an evidence-based addition to these existing programs and approaches. It follows that current at risk retention programs must be understood and funded on the basis of what they can do, such as promoting a sense of inclusiveness and providing pastoral care for at risk groups, and not what university administrators might hope they can do, such as improving overall student retention rates. For this to occur, a more holistic student retention approach based on enhancing student-LMX would appear to offer more targeted - and potentially cost effectiveway forward.

If universities and those who work for them, however, are to enhance student's levels of engagement and retention through the medium of LMX (as the findings herein would suggest), several further considerations are required. In particular, academic prestige, and chances of promotion and career advancement as a consequence, is more generally aligned with academics' research performance (i.e., how many publications, grants and industry linkages that an academic has) compared to their teaching performance. Our findings indicate that perhaps more attention needs to be given to the pedagogical approaches adopted by academic staff. Yet it is important to ensure that LMX not be confused with other indicators of pedagogical performance such as 'student satisfaction scores'. Indeed, the latter is an arguably crude output measure, while the former is designed to account for an exchange process that - as is contended here - lies at the heart of promoting student engagement and retention. Equally, readers should be discouraged from interpreting these results as a need to de-emphasise academic research in order to enhance lecturer-student exchange relationships. This is because research-active lecturers may be better equipped to develop reciprocal student relationships, particularly through the content expert being the leader, and the novice as follower. 
To this end, one of the inadequacies of this study, and consequently a stimulus for future research, is that we require a more thoroughly nuanced understanding with respect to how an LMX relationship forms between teaching staff and their students, and what factors can strengthen it. For example, we need to establish if academics actively researching a topic area relating closely to their teaching are more able to inspire student learning. In addition, we need to understand the prejudices that might lead to some lecturers or tutors forming reciprocal LMX relationships with certain groups of students, at the exclusion of others. As noted by Yorke and Thomas (2003), for overall student engagement and retentions gains to be made, higher education staff responsible for teaching will need to cater the learning experience to the diverse needs, characteristics and attitudes of all student within their classes.

While the control variables used in the analytical model go some way to enhancing the generalisability of the results, expanded replications of this study at other universities (within Australia and internationally) are obviously required to validate the claims herein. However, the findings presented offer significant implications for the way in which student engagement and retention is currently conceptualised by practitioners and theorists. At the very least, universities adopting an agenda that decreases student-lecturer interactions through more online and outsourced learning arrangements may want to review the potential impact of such arrangements in light of our findings.

\section{Limitations}

This study has a number of limitations. In the first instance, the sample, being drawn from a single university with presumably its own individual characteristics, potentially inhibits the broader generalisability of the results. Yet we argue, particularly noting the use of control variables in the model, that the results compel replication and validation. A second limitation concerns the use of self-report survey data in analysis. As noted, while this medium provides an advantageous platform to collect information about individual's behaviours, beliefs and attitudes, it is prone to common method bias (Richardson et al. 2009). However, the robustness test applied to our data indicated a low chance of common method bias, arguably because we applied the survey design suggestions of Cascio (2012) for reducing method variance, in addition to incorporating other data sources into out model (GPA). Finally, the measure of student's 'intention to leave university' is perceptual, and may not represent the totality of student attrition. That noted, the efficacy of this measure in predicting eventual leave/exit is well documented (Sjoberg and Sverke 2000; Tett and Meyer 1993), though not within the context of university attrition. Future replication of the study herein, incorporating additional variables such as eventual turnover and other contextual control variables, is thus suggested.

\section{Conclusion}

LMX applied to the context of lecturer-student exchange relationships, from the data analysis conducted through this study, appears to be a significant predictor of student engagement, course satisfaction and intention to leave university prematurely. Indeed, findings from our study give credence to the proposition that student-LMX provides the basis for measurable approaches to the enhancement of student engagement and retention to their selected higher education setting, irrespective of any at risk categorisation. To date, research conceptualising student-lecturer relationships through the lens of LMX is in its infancy, and the results 
presented in this study clearly prompt: a) future replication, to assure model validity; and b) expansion, for the purpose of understanding how the critical LMX between lecturers and student develops, and how it might be measured effectively for evaluative purposes, since lecturers who are able to engender higher degrees of LMX with their students will ceteris paribus be best placed to improve retention rates. In a climate where traditional universities and other tertiary education or training organisations are increasingly being called upon to improve their productivity and operational sustainability in the face of non-traditional, lessresource-intensive higher education models, focusing on enhancing student-LMX should now be regarded as having empirical support.

\section{References}

Baron, R. M., and Kenny, D. A. (1986). "The Moderator-Mediator Variable Distinction in Social Psychological Research - Conceptual, Strategic and Statistical Considerations." Journal of Personality and Social Psychology, 51(6), 1173-1182.

Becker, T. E. (2005). "Potential Problems in the Statistical Control of Variables in Organizational Research: A Qualitative Analysis with Recommendations." Organisational Research Methods, 8(3), 274-289.

Brunetto, Y., Xerri, M., Shriberg, A., Farr-Wharton, R., Shacklock, K., Newman, S., and Dienger, J. (2013). "The impact of workplace relationships on engagement, wellbeing, commitment and turnover for nurses in Australia and the USA." Journal of Advanced Nursing, 69(12), 2786-2799.

Cammann, C., Fichman, M., Jenkins, G. D., and Kelsh, J. R. (1983). "Assessing the attitudes and perceptions of organizational members.", in S. E. Seashore, E. E. Lawler, P. Mirvis, and C. Cammann, (eds.), Assessing Organizational Change. New York: John Wiley and Sons, pp. 71-138.

Cascio, W. (2012). "Methodological issues in international HR management research." The International Journal of Human Resource Management, 23(12), 2532-2545.

Christie, H., Munro, M., and Fisher, T. (2004). "Leaving university early: exploring the differences between continuing and non-continuing students." Studies in Higher Education, 29(5), 617-636.

Cropanzano, R., and Mitchell, M. S. (2005). "Social Exchange Theory: An Interdisciplinary Review." Journal of Management, 31(December), 874-900.

Edwards, D., and McMillan, J. (2015). "Completing university in a growing sector: Is equity an issue?" Joining the Dots Research Briefing Series, 3(2), 1-12.

Elliott, K. M., and Shin, D. (2002). "Student satisfaction: an alternative approach to assessing this important concept." Journal of Higher Education Policy and Management, 24(2), 197-209.

Farr-Wharton, B., Brown, K., Keast, R., and Shymko, Y. (2015). "Reducing Creative Labour Precarity: more than network structure." Management Decision, 53(4), 857-875. 
Forsman, J., Linder, C., Moll, R., Fraser, D., and Andersson, S. (2014). "A new approach to modelling student retention through an application of complexity thinking." Studies in Higher Education, 39(1), 68-86.

George, D., and Mallery, M. (2010). SPSS for windows step by step: a simple guide and reference, 17.0 update, Boston: Pearson.

Graen, G. B., and Uhl-Bien, M. (1995). "Relationship-based approach to leadership: Development of Leader-Member Exchange (LMX) Theory of leadership over 25 years: applying multi-level, multi-domain perspective." Leadership Quarterly, 6(2), 219-247.

Hair, J. F., Black, W. C., Babin, B. J., and Anderson, R. E. (2010). Multivariate data anlysis: A global perspective, Upper Saddle River, NJ: Pearson Education.

Jacques, P. H., Garger, J., Thomas, M., and Vracheva, V. (2012). "Effects of early LeaderMember Exchange perceptions on academic outcomes." Learning Environment Research, 15(1), 1-15.

Jamelske, E. (2009). "Measuring the impact of a university first-year experience program on student GPA and retention." Higher Education, 57, 373-391.

Jordan, P., and Troth, A. (2011) "Emotional intelligence and leader member exchange: The relationship with employee turnover intentions and job satisfaction." Leadership \& Organization Development Journal, 32(3), 260-280.

Krishen, A. (2013). "Catch it if you can: how contagious motivation improves group projects and course satisfaction." Journal of Marketing Education, 35(3), 220-230.

Mosley, C., Broyles, T., and Kaufman, E. (2014). "Leader-member Exchange, Cognitive Style, and Student Achievement." Journal of Leadership Education(summer), 50-69.

OECD. (2013). Education at a Glance 2013. OECD Publishing.

Paechter, M., Maier, B., and Macher, D. (2010). "Students' expectations of, and experiences in e-learning: Their relation to learning achievements and course satisfaction." Computers \& Education, 54, 222-229.

Richardson, H. A., Simmering, M. J., and Sturman, M. C. (2009). "A Tale of Three Perspectives: examining post hoc statistical techniques for detencion and correction of common method variance." Organizational Research Methods, 12(4), 762-800.

Richardson, J., Slater, J., and Wilson, J. (2007). "The national student survey: Development, findings and implications." Studies in Higher Education, 32(5), 557-580.

Sanchez, R. J., Bauer, T., and Paronta, M. E. (2006). "Peer-Mentoring Freshmen: Implications for Satisfaction, Commitment, and Retention to Graduation." Academy of Management Learning \& Education, 5(1), 25-37.

Schaufeli, W., Martinez, I., Marques Pinto, A., Salanova, M., and Bakker, A. B. (2002). "Burnout and engagement in university students: a cross-national study." Journal of Cross-Cultural Psychology, 33(5), 464-481.

Schneider, M. (2010). Finishing the First Lap: the cost of first-year student attrition in America's Four-Year Colleges and Universities. American Institutes for Research, Washington DC. 
Scott, D. (2005). "Retention, Completion and Progression in Tertiary Education in New Zealand." Journal of Higher Education Policy and Management, 27(1), 3-17.

Scott, D. (2009). "A closer look at completion in higher education in New Zealand." Jounrnal of Higher Education Policy and Management, 31(2), 101-108.

Sevier, R. (1996). "Those important things: what every college president needs to know about marketing and student recruiting." College \& University, 9-16.

Shrout, P. E., and Bolger, N. (2002). "Mediation in experimental and nonexperimental studies: New procedures and recommendations." Psychological Methods, 7, 422-445.

Simpson, O. (2013). "Student retention in distance education: are we failing our students?" Open Learning, 28(2), 105-119.

Sjoberg, A., and Sverke, A. (2000). "The interactive effect of job involvement and organizational commitment on turnover revisted: a note on the mediating role of turnover intention." Scandinavian Journal of Psychology, 41(2), 247-252.

Taylor, J., and Bedford, T. (2004). "Staff perceptions of factors related to non-completion in higher education." Studies in Higher Education, 29(3), 375-394.

Tett, R., and Meyer, R. (1993). "Job Satisfaction, Organizational Commitment, Turnover Intention, and Turnover: Path Analyses based on Meta-Analytic Findings." Personnel Psychology, 46(2), 259-293.

Vaira, M. (2004). "Globalization and higher education organizational change: a framework for analysis." Higher Education, 48(3), 483-510.

Wayne, S., Shore, L. M., and Linden, R. (1997). "Perceived Organisational support and leader exchange: A social exchange perspective." Academy of Management Journal, 40(1), $82-111$.

Wilcox, P., Winn, S., and Fyvie-Gauld, M. (2005). "It was nothing to do with the university, it was just the people': the role of social support in the first-year experience of higher education." Studies in Higher Education, 30(6), 707-722.

Willcoxson, L., Cotter, J., and Joy, S. (2011). "Beyond first-year experience: the impact on attrituion of student experiences through undergraduate degree studies in six diverse universities." Studies in Higher Education, 36(3), 331-352.

Yorke, M., and Thomas, L. (2003). "Improving the retention of students from lower socioeconomic groups." Journal of Higher Education Policy and Management, 25(1), 6374.

Zepke, N., Leach, L., and Prebble, T. (2006). "Being learner centred: one way to improve student retention?" Studies in Higher Education, 31(5), 587-600. 
Figure 1: hypothetical model

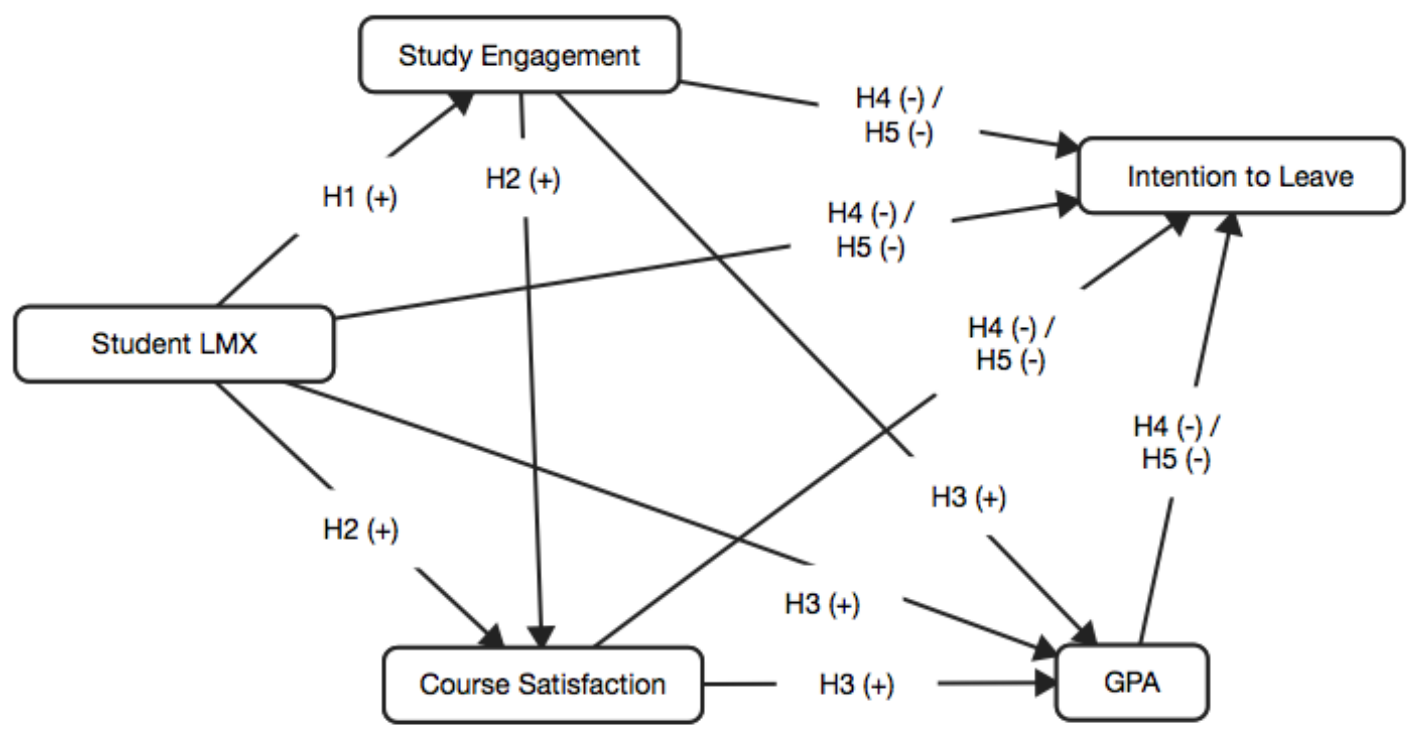

Control variables for Intention to Leave:

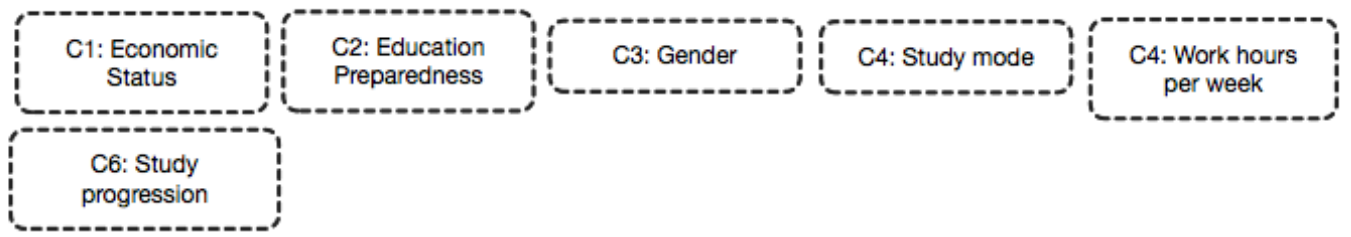

Table I: Reliability and inter-construct correlation

\begin{tabular}{|l|c|c|c|c|c|c|c|c|}
\hline & $\begin{array}{c}\text { Composite } \\
\text { Reliability }\end{array}$ & $\begin{array}{c}\text { Average } \\
\text { Variance } \\
\text { Extracted }\end{array}$ & $\mathbf{1}$ & $\mathbf{2}$ & $\mathbf{3}$ & $\mathbf{4}$ & $\mathbf{5}$ & $\mathbf{6}$ \\
\hline 1. Course Satisfaction & .90 & .69 & $\mathbf{. 8 3}$ & & & & & \\
\hline 2. Student-LMX & .90 & .58 & .73 & $\mathbf{. 7 6} *$ & & & & \\
\hline 3. Engagement & .89 & .57 & .74 & .62 & $\mathbf{. 7 5 *}$ & & & \\
\hline $\begin{array}{l}\text { 4. Intention to Leave } \\
\text { University }\end{array}$ & .94 & .79 & -.45 & -.30 & -.32 & $\mathbf{. 8 9 *}$ & & \\
\hline 5. Economic Status & .85 & .69 & .15 & .18 & .07 & -.06 & $\mathbf{. 8 3} *$ & \\
\hline 6. Edu. Preparedness & .92 & .69 & .27 & .32 & .25 & .07 & .23 & $\mathbf{. 8 3 *}$ \\
\hline
\end{tabular}

*The square root of the average variance extracted is indicated in bold. 
Table II: Descriptive and correlation analysis for constructs

\begin{tabular}{|c|c|c|c|c|c|c|c|c|c|c|c|c|c|c|}
\hline & & Mean & S.D. & 1 & 2 & 3 & 4 & 5 & 6 & 7 & 8 & 9 & 10 & 11 \\
\hline 1 & $\begin{array}{l}\text { Intention to Leave } \\
\text { University }\end{array}$ & 1.5430 & .82785 & 1 & & & & & & & & & & \\
\hline 2 & $\begin{array}{l}\text { GPA } \\
\text { (standardised) }\end{array}$ & 4.3576 & .91008 & -.01 & 1 & & & & & & & & & \\
\hline 3 & $\begin{array}{l}\text { Course } \\
\text { Satisfaction }\end{array}$ & 4.6439 & .97594 & $-.44^{* * *}$ & -.02 & 1 & & & & & & & & \\
\hline 4 & $\begin{array}{l}\text { Student } \\
\text { Engagement }\end{array}$ & 4.0491 & .99614 & $-.33^{* * *}$ & $.11^{*}$ & $.66^{* * *}$ & 1 & & & & & & & \\
\hline 5 & LMX & 4.2605 & .90739 & $-.31^{* * *}$ & .07 & $.66^{* * *}$ & $.60^{* * *}$ & 1 & & & & & & \\
\hline 6 & Edu. Preparedness & 3.9550 & 1.38974 & -.08 & $.12 *$ & $.26^{* * *}$ & $.22^{* * *}$ & $.30^{* * *}$ & 1 & & & & & \\
\hline 7 & Economic status & 3.3994 & 1.46577 & -.06 & -.01 & $.13^{*}$ & .06 & $.16^{* *}$ & $.18^{* * *}$ & 1 & & & & \\
\hline 8 & Work Hours p/w & 2.2369 & 1.31042 & $-.12^{*}$ & .04 & .03 & -.08 & -.08 & .03 & $.26^{* * *}$ & 1 & & & \\
\hline 9 & Study mode & 2.6000 & 1.69100 & .05 & -.06 & -.07 & -.08 & $-.11^{*}$ & .05 & .06 & $.32^{* * *}$ & 1 & & \\
\hline 10 & Year (1 or 2$)$ & 1.6226 & .48541 & .06 & -.04 & .10 & .07 & .01 & .01 & .00 & -.07 & $.24^{* * *}$ & 1 & \\
\hline 11 & Gender & 1.7218 & .44875 & $-.13^{*}$ & .04 & .10 & .02 & .05 & .04 & .04 & -.01 & -.05 & .04 & 1 \\
\hline
\end{tabular}

\section{Figure 2: Path model results}

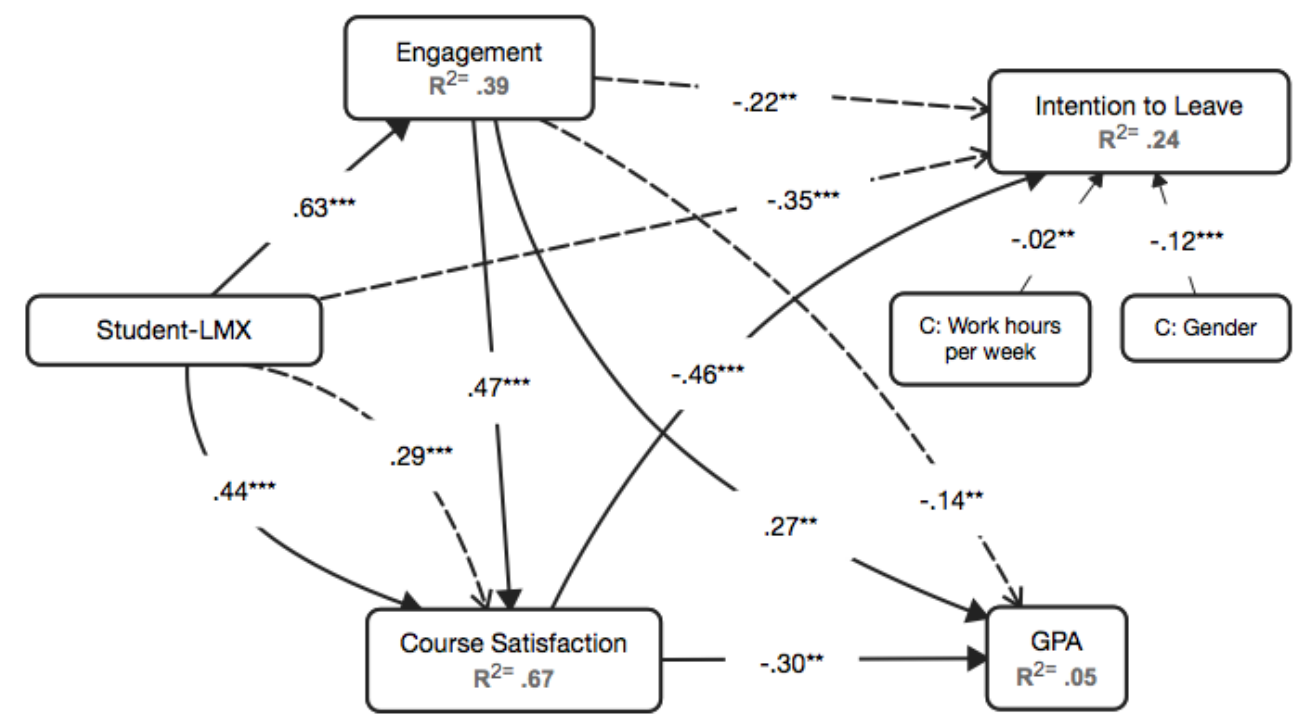

${ }^{* * * *} p<0.001,{ }^{* *} p<0.01,{ }^{*} p<0.05, n=363$. Complete lines represent a significant direct path, dotted lines represent a significant indirect path (see table III for further indirect path testing). 


\begin{tabular}{|l|l|l|l|}
\hline $\begin{array}{l}\text { Table III: Direct, indirect and total } \\
\text { effects Relationship }\end{array}$ & $\begin{array}{l}\text { Direct } \\
\text { Effects }\end{array}$ & $\begin{array}{l}\text { Indirect } \\
\text { Effects }\end{array}$ & $\begin{array}{l}\text { Total } \\
\text { Effects }\end{array}$ \\
\hline LMX -> Engagement & $.63^{* * *}$ & - & $.63^{* * *}$ \\
\hline LMX -> Course Satisfaction & $.44^{* * *}$ & $.29^{* * *}$ & $.73^{* * *}$ \\
\hline LMX -> GPA & - & - & - \\
\hline LMX -> Intention to Leave & - & $-.35^{* * *}$ & $-.35^{* * *}$ \\
\hline Engagement -> Course Satisfaction & $.47^{* * *}$ & - & $.47^{* * *}$ \\
\hline Engagement -> GPA & $.27^{* *}$ & $-.14^{* *}$ & $.13^{* *}$ \\
\hline Engagement -> Intention to Leave & - & $-.22^{* *}$ & $-.22^{* *}$ \\
\hline Course Satisfaction -> GPA & $-.30^{* *}$ & - & $-.30^{*}$ \\
\hline $\begin{array}{l}\text { Course Satisfaction -> Intention to } \\
\text { Leave }\end{array}$ & $-.46^{* * *}$ & - & $-.46^{* * *}$ \\
\hline GPA -> Intention to Leave & - & - & - \\
\hline
\end{tabular}

${ }^{* * *} p<0.001, * * p<0.01,{ }^{*} p<0.05 . n=363$. Total Effects $=$ Direct Effects (estimate and $p$ value) + Indirect Effects (estimate and $p$ value). Indirect confidence interval ( $p$ value) is determined through Two Tailed Bias Corrected (95\% confidence) percentile method bootstrapped to 4000 samples. The hyphen represents an insignificant path. 


\section{Appendix 1 - Questionnaire Items}

\section{Student-LMX (from Graen and Uhl-Bien 1995)}

In general, the lecturing and teaching staff in my subjects;

- $\quad$ are satisfied with my work

- recognise my potential

- understand my study problems and needs

- $\quad$ are willing to use their position to help me solve study problems

- would be willing to help me in their own time

- make good decisions and I would defend or justify these decisions if they were not present to do so

- Encourage a good learning relationship

\section{Student Engagement (from Schaufeli et al. 2002)}

I am bursting with energy

I find the study that I do full of meaning and purpose

Time flies when I am doing my university studies

When I get up in the morning, I feel like doing my university studies

I am enthusiastic about my university studies

I am immersed in my university studies

I feel happy when I am studying intensely

\section{Course Engagement}

On the whole the learning experiences and content in the course that I am currently enrolled in:

- $\quad$ are what I expected

- $\quad$ are interesting

- $\quad$ equip me with the skills I need to achieve my career goals in the future

- leave me feeling satisfied

Intention to Leave University (from Cammann et al. 1983)

I frequently think about leaving this university 
I am searching for other employment or study opportunities so I can leave this university

It is likely that I would actually leave this university within the next year

I am exploring opportunities to leave my studies

Economic Status (adapted from Farr-Wharton et al. 2015)

My income is on par to people my own age

I have the ability to purchase items that I want

I have the ability to purchase items that I need

I have enough money to live well

I don't experience financial hardship

I am satisfied with the income that I have

\section{Educational preparedness}

My previous education has prepared me well for my current studies

My achievement at university is similar to my achievement in the previous education I have done

My previous education was of quality 